\section{The Voice of Canadian General Internists}

As a new decade is upon us, it is an opportunity for some of us to reflect on the past decade's accomplishments and milestones achieved whereas for others it is simply another fleeting moment on the space-time continuum. As I write, on this palindromic (02022020) day, this space provides me the privileged opportunity to share my reflections on the Journal and, with some humility, on our journey as clinicians in the world of general internal medicine.

The Canadian Journal of General Internal Medicine - your journal - is entering its third decade of existence, having been launched in 2006 by Dr. Hector Baillie who is now an ongoing contributor to the "Casebook of a Community Internist" segment of the Journal. More recently, the Journal was been led by Dr. Mitchell Levine who increased its academic profile and transitioned the Journal to an online format allowing us to reach a broader audience in a more cost-efficient (and tree-sparing) manner. As I enter the third year of my tenure as editor-in-chief, my foremost goal for the current decade is to have the Journal achieve indexing status by the U.S. National Library of Medicine. Along with deputy editors, Drs. Rodrigo Cavalcanti, Ameen Patel, and John You, we have started the process towards this goal, and when (not if) achieved, it will provide the springboard to attract the highest scholarship in general internal medicine (GIM) in Canada and abroad. However, we will always retain the Journal's mission of being the voice of Canadian general internists.

Indeed, the chorus of voices belonging to general internists has also, in the last decade, swelled to an overwhelming crescendo. The catalyst, in my view, occurred in 2011 when the Royal College of Physicians and Surgeons of Canada granted subspecialty status to GIM. This change, coupled with the development of GIM training programs across Canada led by many dedicated program directors, has led to a surge of interest in GIM which has become one of the most desired destinations for medical school graduates. One can safely say that in medical practice, the 10 s were the decade of GIM in Canada.

Finally, in the midst of the ongoing novel coronavirus epidemic, we can also reflect on our fortunate positions as general internists in a country with a health care system which, though imperfect, remains the envy of many other nations. Let us embrace the new decade with vigour, determination, and humility.

\section{James Douketis MD}

Editor-in-Chief

Canadian Journal of General Internal Medicine

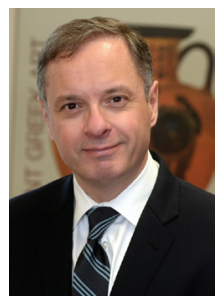

